\title{
Identifying the symptom and functional domains in patients with fibromyalgia: results of a cross- sectional Internet-based survey in Italy
}

This article was published in the following Dove Press journal:

Journal of Pain Research

13 May 2016

Number of times this article has been viewed

\author{
Fausto Salaffi ${ }^{1}$ \\ Flavio Mozzani² \\ Antonella Draghessi' \\ Fabiola Atzeni ${ }^{3}$ \\ Rosita Catellani \\ Alessandro Ciapetti ${ }^{4}$ \\ Marco Di Carlo' \\ Piercarlo Sarzi-Puttini ${ }^{5}$ \\ 'Rheumatology Department, \\ Polytechnic University of Marche, \\ Jesi (Ancona), ${ }^{2}$ Department of \\ Internal Medicine and Rheumatology, \\ University Hospital of Parma, \\ Parma, ${ }^{3}$ RCCS Galeazzi Orthopedic \\ Department, Milan, Italy; \\ ${ }^{4}$ Rheumatology Department, Betsi \\ Cadwaladr University Health Board, \\ Glan Clwyd Hospital, Bodelwyddan, \\ Denbighshire, Wales; ${ }^{5}$ Rheumatology \\ Department, L. Sacco University \\ Hospital, Milan, Italy
}

Objective: The aims of this cross-sectional study were to investigate the usefulness of using an Internet survey of patients with fibromyalgia in order to obtain information concerning symptoms and functionality and identify clusters of clinical features that can distinguish patient subsets.

Methods: An Internet website has been used to collect data. Fibromyalgia Impact Questionnaire Revised version, self-administered Fibromyalgia Activity Score, and Self-Administered Pain Scale were used as questionnaires. Hierarchical agglomerative clustering was applied to the data obtained in order to identify symptoms and functional-based subgroups.

Results: Three hundred and fifty-three patients completed the study ( $85.3 \%$ women). The highest scored items were those related to sleep quality, fatigue/energy, pain, stiffness, degree of tenderness, balance problems, and environmental sensitivity. A high proportion of patients reported pain in the neck (81.4\%), upper back (70.1\%), and lower back (83.2\%). A three-cluster solution best fitted the data. The variables were significantly different $(P<0.0001)$ among the three clusters: cluster 1 (117 patients) reflected the lowest average scores across all symptoms, cluster 3 (116 patients) the highest scores, and cluster 2 (120 patients) captured moderate symptom levels, with low depression and anxiety.

Conclusion: Three subgroups of fibromyalgia samples in a large cohort of patients have been identified by using an Internet survey. This approach could provide rationale to support the study of individualized clinical evaluation and may be used to identify optimal treatment strategies.

Keywords: fibromyalgia, Internet, FIQR, FAS, cluster analysis, SAPS, pain

\section{Introduction}

Fibromyalgia (FM) is a chronic heterogeneous syndrome that affects $\sim 2 \%-3 \%$ of the general population. ${ }^{1-3}$ Its primary symptom is chronic, widespread pain associated with generalized tenderness on light palpation. Many patients report a multitude of additional complaints and symptoms, ${ }^{4}$ including fatigue, exhaustibility and stiffness, and impaired concentration and memory (a complaint that is increasingly recognized as an independent symptom, namely, "fibrofog" or "dyscognition", according to medical literature). ${ }^{5}$ The combinations and severity of symptoms may vary from patient to patient, and this makes it difficult to understand the disease and the development of appropriate treatment strategies. ${ }^{6}$ However, stratifying patients by cluster analysis into more homogeneous subgroups on the basis of their patient-relevant clinical features may help to overcome these limitations. ${ }^{7-14}$ Cluster analysis allows to identify clinical features and quantifies the importance of each cluster. ${ }^{15,16}$

A comprehensive assessment of main symptoms and the evaluation of the impact on the multidimensional aspects of function should be a routine part of patient care
Correspondence: Fausto Salaffi Rheumatology Dapartment, Polytechnic University of Marche, Carlo Urbani Hospital, Jesi (Ancona), Via Aldo Moro, 25, 60035, Italy

Email fausto.salaffi@gmail.com (c) (i) 2016 Salaffi et al. This work is published and licensed by Dove Medical Press Limited. The full terms of this license are available at https://www.dovepress.com/terms. cc) ${ }_{\mathrm{BY}} \mathrm{NC}$ php and incorporate the Creative Commons Attribution - Non Commercial (unported, v3.0) License (http://creativecommons.org/licenses/by-nd/3.0/). By accessing the work you hereby accept the Terms. Non-commercial uses of the work are permitted without any further permission from Dove Medical Press Limited, provided the work is properly attributed. For

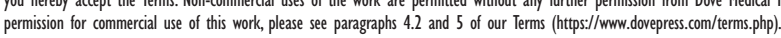


in FM. Patient-reported outcomes (PROs) are playing an increasingly significant role in the evaluation of symptoms, health-related quality of life, and medical compliance. ${ }^{17}$ The Fibromyalgia Impact Questionnaire Revised version (FIQR) is currently the recommended tool for assessing function and health-related quality of life in patients with FM. FIQR assesses six domains (pain, tenderness, fatigue, stiffness, multidimensional function, and sleep) identified as core dimensions by Outcome Measures in Rheumatology Clinical Trials. ${ }^{18}$ Psychometric properties of FIQR (ie, rating scale functioning, internal construct validity, reliability indices, and dimensionality) have been validated. ${ }^{19,20}$ Routine PROs collection can be facilitated by using more advanced interactive computer technologies such as Internet-based home telemonitoring and can support a transition from institution to patient-centered applications. ${ }^{21-26}$

The aims of this cross-sectional study were to investigate the usefulness of an Internet-based national survey of patients with FM in order to obtain information concerning symptoms and functionality and to identify clusters of symptoms that helps to distinguish patient subsets.

\section{Methods}

\section{Study population}

The participants were selected from a large database of patients with FM referring to the Rheumatology Department of the Polytechnic University of Marche in Jesi (Ancona, Italy), the Internal Medicine and Rheumatology Unit of Parma Hospital, and the Rheumatology Unit of "L. Sacco" University Hospital in Milan (Italy). The following subjects have been excluded from the study: those affected by cardiovascular disease, moderate-to-severe chronic lung disease, uncontrolled hypertension, uncontrolled thyroid disturbances, inflammatory rheumatic conditions (ie, rheumatoid arthritis, systemic lupus erythematosus, and other connective tissue diseases), and/or psychoses or active suicidal ideation. A total of 496 patients have been screened, of which 143 refused to participate. The remaining 353 patients satisfied the American College of Rheumatology classification criteria for FM. ${ }^{27}$ All patients have provided written informed consent, and the study was approved by the hospital Ethics Committee (Comitato Unico Regionale - ASUR Marche).

\section{Internet-based PROs}

The patients logged into the website (http://www.fibromialgiaitalia.it) developed for the present study. During the first login to the website, each patient was asked to provide consent and to complete the questionnaires. The questions were displayed using radio buttons. Each question had to be completed before the software continued to the following page. During the first visit, each patient has received a secure username/password combination in order to have access to the website and a brief training on the use of FIQR ${ }^{19}$ and the self-administered Fibromyalgia Activity Score (FAS) ${ }^{28}$ questionnaires. The FIQR was developed by Burckhardt et $\mathrm{al}^{29}$ in an attempt to address the limitations of the original FIQ. ${ }^{29}$ The Italian version of $\mathrm{FIQ}^{20}$ is composed of 21 items that are rated using an 11-point numerical scale (0-10, with 10 being the worst) and cover three domains: physical function, overall impact, and symptoms over the previous 7 days. The total score for the 9-item "function domain" (range: 0-90) is divided by three, the total score for the 2-item "overall impact domain" (range: 0-20) is divided by one, and the total score for the 10-item "symptom domain" (range: 0-100) is divided by two. The global score is given by the sum of the scores of the three domains (range: 0-100). FM is classified as mild (from 0 to 38), moderate (from 39 to 58), or severe (from 59 to 100). ${ }^{30}$ The FAS is a valid, reliable, and responsive disease-specific composite measure for patients with FM. ${ }^{30}$ The FAS index combines scores related to fatigue (range: 0-10) and the quality of sleep (range: 0-10) and scores obtained by the Self-Administered Pain Scale (SAPS) in order to provide a single measure of disease activity (range: 0-10). The SAPS asks patients to classify pain in 16 nonarticular sites ( $0=$ none, $1=$ mild, $2=$ moderate, $3=$ severe), and the final total score of $0-48$ is transformed into a scale of 0-10. At the end of the study, the electronically collected raw data were extracted as anonymous. The database was completed by the demographic characteristics of the patients.

\section{Statistical analysis}

The descriptive statistics of the continuous variables are given as mean values \pm standard deviation and median values with their 25 th to 75 th percentiles, and those of the categorical variables as absolute numbers and percentages. The number of clusters was chosen by examining the dendrogram and considering clinical interpretability and usefulness. The variables of interest in the clusters were subsequently compared using analysis of variance followed by between-cluster pairwise comparisons with Bonferroni adjustment to a significance level of 0.05 . Analysis of variance was also used to compare the behavior of the measured clinical subscales of the FIQR in the defined FM subgroups. The level of significance for all of the tests was $5 \%$. The data were analyzed using the 
Table I Participant demographics $(\mathrm{n}=353)$

\begin{tabular}{|c|c|}
\hline Characteristics & Mean (SD) or $n(\%)$ \\
\hline \multicolumn{2}{|l|}{ Sex } \\
\hline Female, n (\%) & $30 \mathrm{I}(85.3)$ \\
\hline Male, n (\%) & $52(14.7)$ \\
\hline Age, years (SD) & $50.9(11.3)$ \\
\hline Disease duration, years, mean (SD) & $4.7(3.8)$ \\
\hline \multicolumn{2}{|l|}{ Education } \\
\hline Primary school, n (\%) & $38(10.7)$ \\
\hline Secondary school, n (\%) & $230(65.2)$ \\
\hline High school/university, n (\%) & $85(24.1)$ \\
\hline \multicolumn{2}{|l|}{ Employment status } \\
\hline Employed, n (\%) & $182(5 \mid .5)$ \\
\hline Work disabled, n (\%) & $31(8.8)$ \\
\hline $\begin{array}{l}\text { Other (student, full-time homemaker, } \\
\text { other), } \mathrm{n}(\%)\end{array}$ & $79(22.4)$ \\
\hline Unemployed, n (\%) & $61(17.3)$ \\
\hline \multicolumn{2}{|l|}{ Marital status } \\
\hline Married, n (\%) & $215(60.8)$ \\
\hline Divorced/separated, n (\%) & $49(13.8)$ \\
\hline Single, $n(\%)$ & $64(18.3)$ \\
\hline Widowed, n (\%) & $25(7.1)$ \\
\hline $\mathrm{BMI}, \mathrm{kg} / \mathrm{m}^{2}$, mean (SD) & $28.5(5.2)$ \\
\hline
\end{tabular}

Abbreviations: BMI, body mass index; SD, standard deviation.
Statistical Package for Social Sciences, Windows release 11.0 (SPSS Inc., Chicago, IL, USA), and MedCalc, version 12.7.0 (Mariakerke, Belgium).

\section{Results}

\section{Demographic characteristics}

Table 1 shows the demographic characteristics of the 353 responders $(85.3 \%$ women). Mean age of responders was 50.9 years, $60.8 \%$ were married and only $24.1 \%$ had a high school/university education. The mean duration of pain was 4.7 years (range: $1-18$ years). Patients were moderately overweight as their mean body mass index was 28.5 (body mass index of $>25$ and $>30$ were found in $40 \%$ and $7 \%$ of cases, respectively). No significant differences of demographic characteristics were observed between patients who agreed to participate in the study and those who did not.

\section{Descriptive statistics}

Table 2 shows FIQR item, subscale, and total scores. The highest scoring items (those with the greatest disease impact) were the following symptoms related: sleep quality (FIQR15),

Table 2 Scores obtained on the FIQR (mean and median values, SDs and 95\% confidence intervals for each item, subdimensions and total score of the FIQR, and for total score of the FAS) by the study patients ( $n=353$ )

\begin{tabular}{|c|c|c|c|c|c|}
\hline \multicolumn{2}{|c|}{$\begin{array}{l}\text { Item } \\
\text { number }\end{array}$} & Mean & SD & Median & $\begin{array}{l}\text { 25-75th } \\
\text { Percentiles }\end{array}$ \\
\hline I & Brush or comb hair & 3.82 & 2.34 & 4.00 & $2.00-5.00$ \\
\hline 2 & Walk continuously for 20 minutes & 3.78 & 2.84 & 3.00 & $2.00-6.00$ \\
\hline 3 & Prepare a homemade meal & 3.46 & 2.39 & 3.00 & $2.00-5.00$ \\
\hline 4 & Vacuum, scrub, or sweep floors & 4.87 & 2.85 & 5.00 & $3.00-7.00$ \\
\hline 5 & Lift and carry a bag full of groceries & 5.18 & 2.97 & 5.00 & $3.00-8.00$ \\
\hline 6 & Climb one flight of stairs & 4.72 & 2.32 & 5.00 & $3.00-7.00$ \\
\hline 7 & Change bed sheets & 4.72 & 2.64 & 5.00 & $3.00-7.00$ \\
\hline 8 & Sit in a chair for 45 minutes & 4.82 & 2.79 & 5.00 & $3.00-7.00$ \\
\hline 9 & Go shopping for groceries & 4.23 & 2.77 & 4.00 & $2.00-7.00$ \\
\hline \multicolumn{2}{|c|}{ FIQR function subtotal } & 12.36 & 6.81 & 11.70 & $6.30-17.70$ \\
\hline 10 & Cannot achieve goals & 4.49 & 2.69 & 5.00 & $2.00-7.00$ \\
\hline 11 & Feel overwhelmed & 4.67 & 2.73 & 5.00 & $2.00-7.00$ \\
\hline \multicolumn{2}{|c|}{ FIQR overall impact subtotal } & 9.16 & 5.64 & 8.00 & $4.00-13.00$ \\
\hline 12 & Pain rating & 5.69 & 2.32 & 6.00 & $4.00-8.00$ \\
\hline 13 & Fatigue rating & 6.04 & 2.54 & 6.00 & $4.00-8.00$ \\
\hline 14 & Stiffness rating & 5.64 & 2.45 & 6.00 & $4.00-8.00$ \\
\hline 15 & Sleep quality & 6.18 & 2.57 & 6.00 & $4.00-8.00$ \\
\hline 16 & Depression level & 4.94 & 2.49 & 5.00 & $3.00-7.00$ \\
\hline 17 & Memory problems & 4.90 & 2.33 & 5.00 & $3.00-7.00$ \\
\hline 18 & Anxiety level & 4.99 & 2.46 & 4.00 & $3.00-7.00$ \\
\hline 19 & Tenderness level & 5.42 & 2.42 & 6.00 & $4.00-7.00$ \\
\hline 20 & Balance problems & 5.33 & 2.01 & 5.50 & $4.00-7.00$ \\
\hline 21 & Environmental sensitivity & 5.32 & 2.48 & 6.00 & $3.00-7.00$ \\
\hline \multicolumn{2}{|c|}{ FIQR symptoms subtotal } & 26.76 & 8.78 & 27.50 & $20.50-33.50$ \\
\hline \multicolumn{2}{|c|}{ FIQR total score } & 48.28 & 19.20 & 47.65 & $32.30-63.50$ \\
\hline
\end{tabular}

Abbreviations: FAS, Fibromyalgia Activity Score; FIQR, Fibromyalgia Impact Questionnaire Revised version; SD, standard deviation. 
fatigue/energy (FIQR13), pain (FIQR12), stiffness (FIQR14), tenderness (FIQR19), balance problems (FIQR20), and environmental sensitivity (FIQR21). The lowest scored items included functional activities such as brushing/combing hair (FIQR1), preparing a home-made meal (FIQR3), walking continuously for 20 minutes (FIQR2), shopping for groceries (FIQR9), and changing bed sheets (FIQR7).

Figure 1 shows the distribution of the FIQR scores. The impact of the disease on functional domains such as personal care (FIQR1) and activities of daily living (FIQR3, FIQR4, FIQR5, FIQR7, and FIQR9) was greater among women, but the differences were not significant. Similarly, pain (FIQR12), fatigue (FIQR13), rigidity (FIQR14), and sleep quality (FIQR15) were not significantly associated with sex.

SAPS was used to assess the presence of pain in 16 body sites. A high proportion of patients reported pain in the neck (81.4\%), upper back (70.1\%), and lower back $(83.2 \%)$ (Figure 2). There was no difference between sexes in relation to any of the sites.

\section{Cluster analysis}

It was used hierarchical agglomerative clustering of the 21 subscales of the FIQR, respectively, accounting for $33.1 \%$, $34 \%$, and $32.9 \%$ of the sample. The three-cluster solution distinguished three broad levels of severity. Clusters 1 and 3 correspond to the lowest and highest average scores, respectively, and cluster 2 to lower levels of depression, anxiety, and less severe memory problems compared to the other scales of the FIQR (Table 3 and Figure 3). The pairwise comparisons showed significant differences between each cluster for all but a few symptoms. Clusters 2 and 3 were not significantly different in terms of walking continuously for 20 minutes $(P=0.11)$ or lifting and carrying a bag full of groceries $(P=0.21)$ (Figure 3$)$.

\section{Discussion}

Over the last few years, the ongoing evolution of computer software and technology has greatly improved the ability to collect PROs data. One major advantage of computerized questionnaires is to collect good-quality data without any missing or problematic responses commonly found by using paper questionnaires. ${ }^{21-25,31}$ Online surveys enable respondents to answer questionnaires according to their preferences (eg, ways and connection times) while connected to the Internet browser. ${ }^{22-24}$

Our questionnaire was completed by 353 patients with FM, and demographic features of respondents were similar to previous epidemiologic studies and surveys. ${ }^{17,28,32-34}$ Respondents have reported several symptoms mainly including poor quality sleeping, fatigue/lack of energy, pain, stiffness, tender-

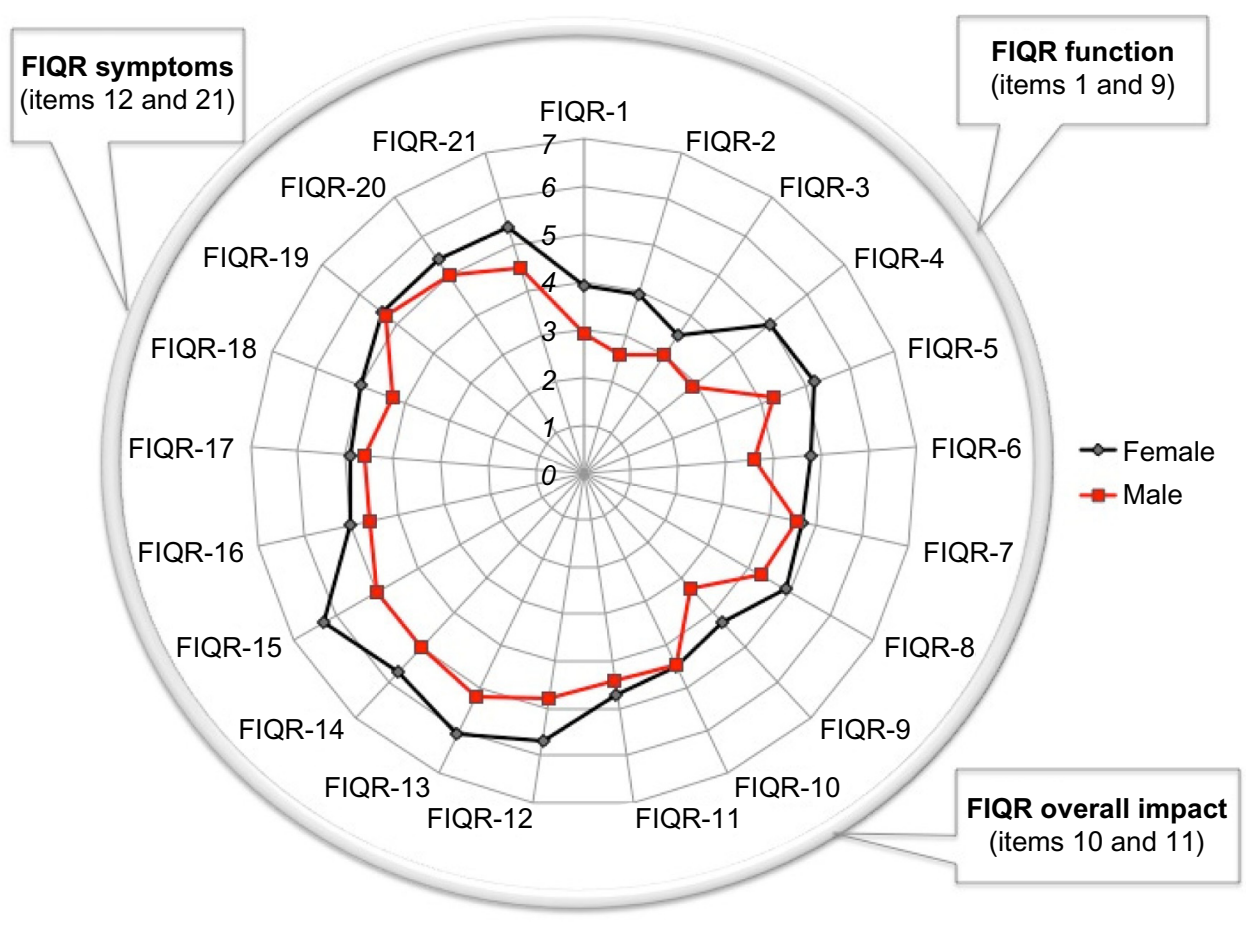

Figure I Spydergrams of the FIQR domains.

Notes: The domain scores are plotted from 0 (best, at the center) to 10 (worst, at the outside).

Abbreviation: FIQR, Fibromyalgia Impact Questionnaire Revised version. 


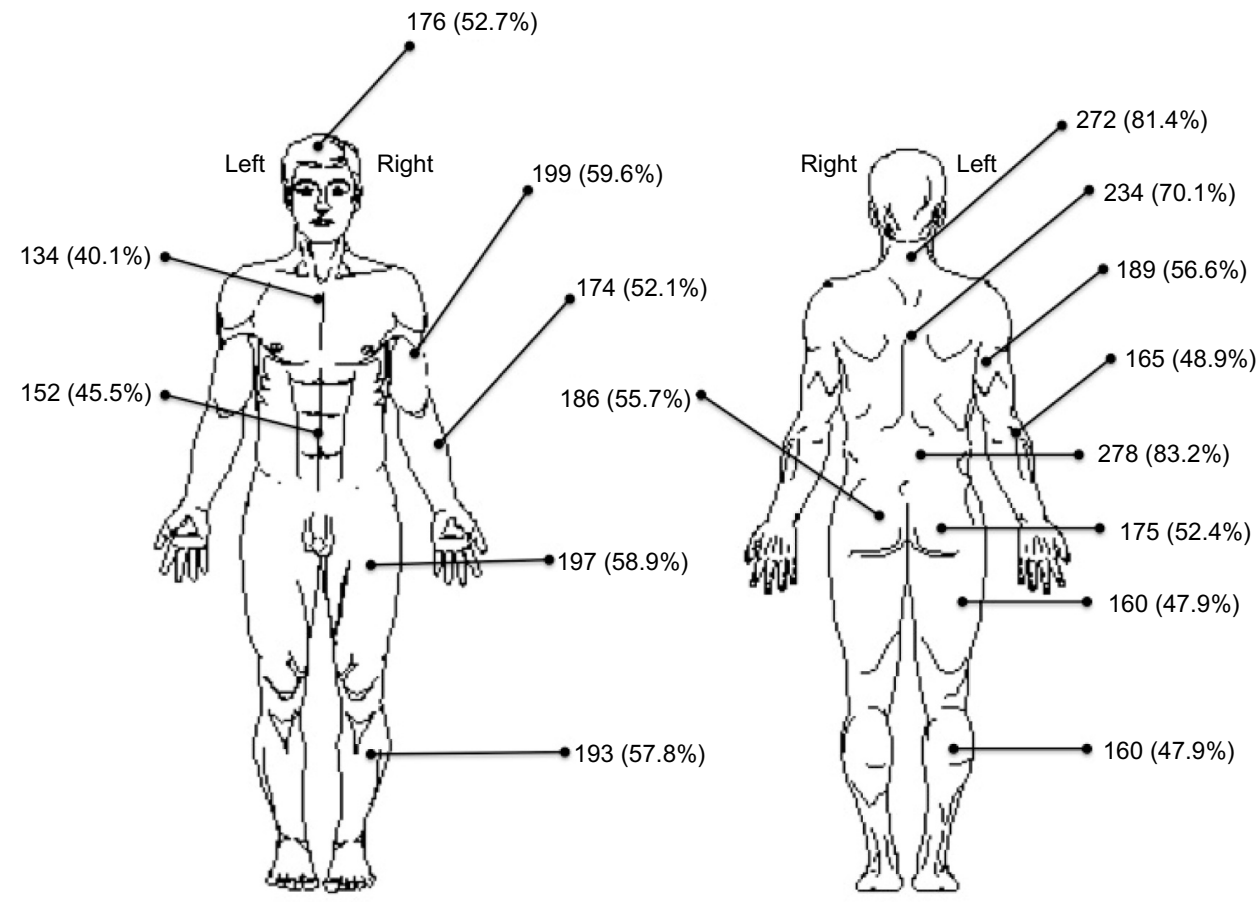

Figure 2 Pain by location expressed in terms of percentage (\%) as revealed by the Self-Administered Pain Scale.

Note: Data are presented as $\mathrm{n}(\%)$.

Table 3 Subgrouping of fibromyalgia samples based on scores obtained on the FIQR (mean and standard deviations) for each item, subdimensions and total score

\begin{tabular}{|c|c|c|c|c|c|c|c|c|}
\hline \multirow[t]{2}{*}{ Item no } & \multirow[t]{2}{*}{ Item description } & \multicolumn{2}{|c|}{ Cluster I $(n=|| 7)$} & \multicolumn{2}{|c|}{ Cluster $2(n=120)$} & \multicolumn{2}{|c|}{ Cluster $3(n=|| 6)$} & \multirow[t]{2}{*}{ F-ratic } \\
\hline & & Mean & SD & Mean & SD & Mean & SD & \\
\hline I & Brush or comb hair & 1.64 & 1.05 & 4.14 & 1.95 & 5.70 & 1.81 & 178.90 \\
\hline 2 & Walk continuously for 20 minutes & 1.75 & 1.54 & 4.22 & 3.02 & 5.38 & 2.44 & 67.51 \\
\hline 3 & Prepare a homemade meal & $\mathrm{I} .44$ & 1.09 & 3.30 & 1.85 & 5.69 & 1.90 & 192.73 \\
\hline 4 & Vacuum, scrub, or sweep floors & 2.74 & 1.40 & 4.97 & 3.03 & 6.94 & 2.11 & 98.36 \\
\hline 5 & Lift and carry a bag full of groceries & 3.16 & 2.32 & 5.45 & 2.95 & 6.95 & 2.26 & 65.83 \\
\hline 6 & Climb one flight of stairs & 2.39 & 1.46 & 5.28 & 1.62 & 6.51 & 1.59 & 213.56 \\
\hline 7 & Change bed sheets & 2.73 & 2.17 & 4.53 & 1.99 & 6.94 & 1.86 & 126.76 \\
\hline 8 & Sit in a chair for 45 minutes & 2.85 & 2.18 & 4.80 & 2.60 & 6.85 & 1.99 & 88.64 \\
\hline 9 & Go shopping for groceries & 1.61 & 1.37 & 4.39 & 1.98 & 6.74 & 2.05 & 227.56 \\
\hline \multicolumn{2}{|c|}{ FIQR physical function } & 6.50 & 3.64 & 13.62 & 6.06 & 17.02 & 5.65 & 123.37 \\
\hline 10 & Cannot achieve goals & 2.04 & 1.78 & 4.54 & 1.93 & 6.94 & 1.67 & 216.11 \\
\hline II & Feel overwhelmed & 1.87 & 1.56 & 5.13 & 1.86 & 7.05 & 1.71 & 271.60 \\
\hline \multicolumn{2}{|c|}{ FIQR overall impact } & 4.00 & 3.93 & 10.13 & 4.96 & 11.35 & 4.97 & 84.44 \\
\hline 12 & Pain rating & 3.13 & $\mathrm{I} .43$ & 6.35 & 1.47 & 7.62 & 1.18 & 343.82 \\
\hline 13 & Fatigue rating & 3.60 & 1.83 & 6.09 & 1.56 & 8.49 & 1.34 & 287.57 \\
\hline 14 & Stiffness rating & 3.16 & 1.50 & 6.01 & 1.67 & 7.79 & 1.46 & 276.56 \\
\hline 15 & Sleep quality & 3.59 & 1.86 & 6.55 & 1.51 & 8.44 & 1.52 & 270.29 \\
\hline 16 & Depression level & 2.55 & 1.39 & 4.46 & 0.95 & 7.87 & 1.21 & 589.57 \\
\hline 17 & Memory problems & 2.66 & 1.35 & 4.55 & 1.07 & 7.54 & 1.18 & 487.14 \\
\hline 18 & Anxiety level & 3.01 & $\mathrm{I} .48$ & 4.16 & 0.93 & 7.86 & 1.58 & 401.85 \\
\hline 19 & Tenderness level & 3.30 & 2.08 & 5.85 & 1.85 & 7.13 & 1.50 & 137.22 \\
\hline 20 & Balance problems & 3.34 & 1.42 & 5.72 & 1.22 & 6.96 & 1.37 & 219.63 \\
\hline 21 & Environmental sensitivity & 2.66 & 1.64 & 6.00 & 1.39 & 7.31 & 1.59 & 281.67 \\
\hline \multicolumn{2}{|c|}{ FIQR symptoms } & 18.06 & 5.94 & 28.12 & 6.10 & 34.19 & 5.21 & 233.51 \\
\hline \multicolumn{2}{|c|}{ FIQR total } & 28.57 & 10.31 & 51.88 & 14.77 & 62.57 & 13.44 & 210.32 \\
\hline
\end{tabular}

Notes: Cluster I reflecting the lowest average levels across all symptoms, cluster 3 reflecting the highest average levels across all symptoms, and cluster 2 capturing moderate symptom levels with lower levels of depression, anxiety, and memory problems.

Abbreviations: FIQR, Fibromyalgia Impact Questionnaire Revised version; SD, standard deviation; no, number. 


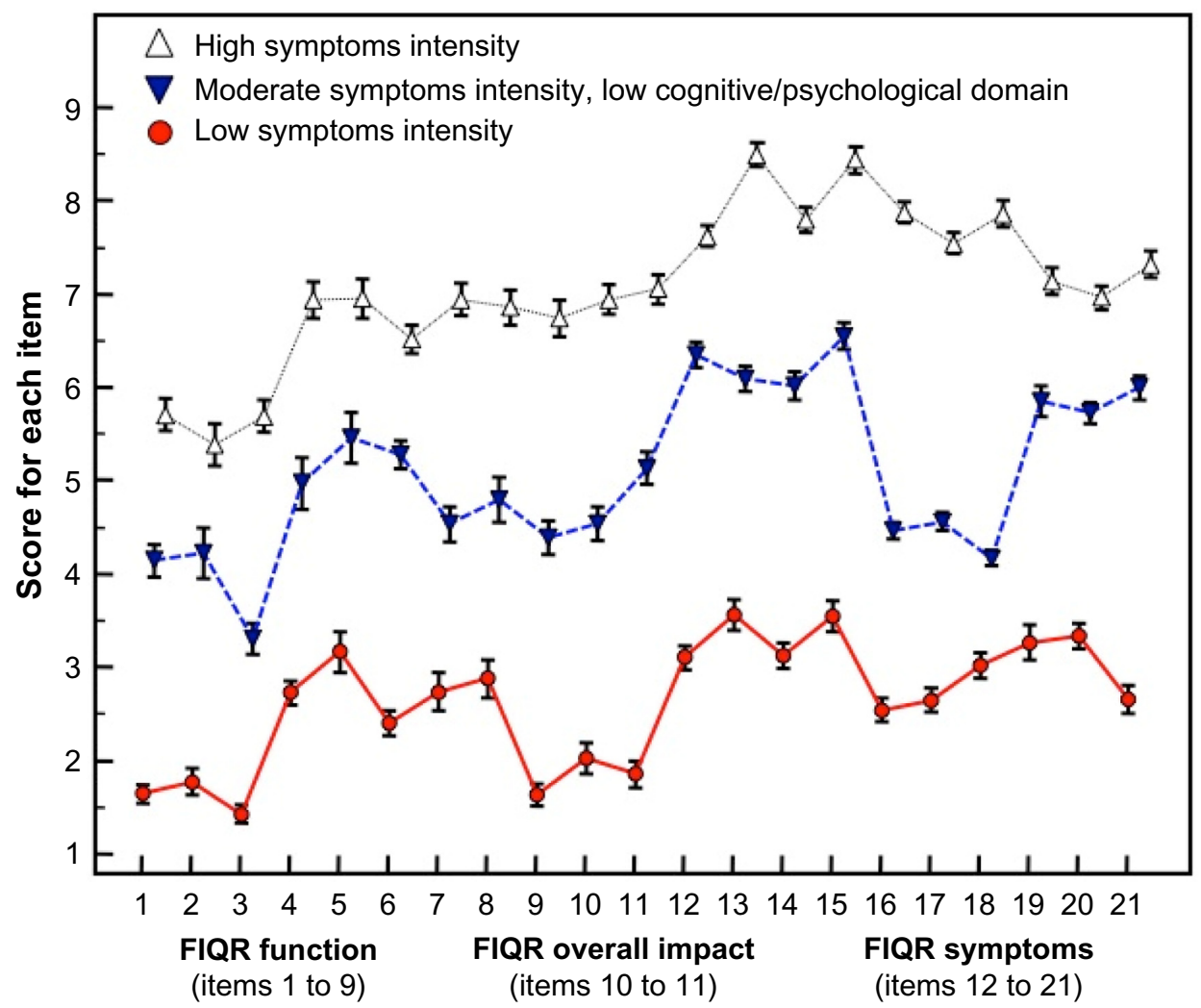

Figure 3 Cluster profiles.

Notes: Cluster I ( $n=117$, red line) showed generally low symptom intensity; cluster 2 ( $n=120$, blue line) was characterized by moderate symptoms and low cognitive/ psychological domain scores; cluster 3 ( $n=116$, gray line) showed the least control over pain, considerable tenderness, high symptom levels, and considerable cognitive/ psychological problems.

Abbreviation: FIQR, Fibromyalgia Impact Questionnaire Revised version.

ness, and increasing environmental sensitivity. There were no significant differences between sexes in these domains. The tendency for women to have higher scores in some domains (eg, brushing/combing hair, preparing home-made meals, vacuum cleaning, scrubbing/sweeping floors, or shopping) seems related to the fact that those daily activities are peculiar to female sex.

Cluster analysis has revealed three distinctive subgroups of symptoms: cluster 1 lowest mean total FIQR and FIQR scores (ranging from 0 to $\leq 39$ ) ${ }^{35}$ cluster 2 moderate symptoms and mild levels of cognitive/psychological impairment (scores ranging from 39 to $\leq 59$ ); and cluster 3 severe symptoms (scores ranging from 59 to 100). Our findings have some similarities with results from previous cluster analyses in patients with FM. Vincent et $\mathrm{al}^{15}$ found that a four-cluster solution best fit their results: clusters 1 and 4 correspond to the lowest and highest scores among all symptoms and clusters 2 and 3 intermediate levels of anxiety and depression, with cluster 2 having lower levels of depression and anxiety than cluster 3, despite higher levels of pain. Similarly, the cluster analysis of Wilson et $\mathrm{al}^{36}$ identified four clusters: cluster 1 had high scores in all three domains, cluster 2 had moderate scores in the two physical symptoms domains and high cognitive/psychological symptom scores, cluster 3 had moderate scores in the two physical symptoms domains and low cognitive/ psychological symptoms scores, and cluster 4 had low scores in all symptoms domains. Clusters 2 and 3 were therefore distinguished by differences in the severity of depression and anxiety, which is also consistent with the findings of Giesecke et al. ${ }^{8}$ In this study, the authors have identified three patient-subsets mainly on the basis of differences in pain and psychopathology as follows: first one characterized by moderate levels of mood, catastrophizing and perceived pain control, and low levels of tenderness; second one characterized by high degree of mental impairment, highest catastrophizing subscales and severe pain; third one characterized by normal mood ratings, very low levels of catastrophizing and the highest level of perceived pain control even though they showed extreme tenderness when evoked pain was tested. However, our findings are not directly comparable with those of these studies ${ }^{8,15,36}$ because they used measurements of experimental pain and some variables were not included in our study. 
De Souza et al ${ }^{13}$ also highlighted anxiety and depression as differentiating factors in their two-cluster model based on the FIQ: both FM subgroups showed hyperalgesic responses to experimental pain, but type I was characterized by the lowest levels of anxiety, depression, and morning tiredness and type II by high levels of pain, fatigue, morning tiredness, stiffness, anxiety, and depression. Similarly, Docampo et $\mathrm{l}^{37}$ have identified three subgroups in a series of 1,446 Spanish patients. One with low symptom scores and few comorbidities; second one with high symptom scores and multiple comorbidities; and third one with high symptom scores but few comorbidities. Psychological and cognitive impairments (such as memory deficits) are associated with a wide variety of pain conditions. ${ }^{38-40}$ The fact that these clinical features seem to be more severe in patients with FM suggested that a group of alterations in a disorder may enhance the magnitude of specific symptoms such as pain. Williams et $\mathrm{al}^{41}$ found that the domains of mood and fatigue were closely associated with perceived dyscognitions in FM, whereas pain was uniquely associated with perceived language deficits and, unexpectedly, was not related to attention or concentration. In line with this, our findings indicate that memory problems and psychological symptoms (anxiety and depression) were not associated with pain intensity in cluster 2 .

Our study has some methodological limitations. First of all, the use of the Internet browser was associated with various socioeconomic and demographic factors, including age, sex, location, and education, and users could not to be representative of target population. However, Internet-based assessments have been accepted by a sizeable percentage (71.2\%) of the eligible patients. Second, we did not select patients on the basis of their ongoing pharmacological therapy, although this is an important factor that may mediate dyscognition in FM. It is extremely rare to find a diagnosed subject who is not taking continuous doses of antidepressants (eg, amitriptyline, duloxetine), antiepileptic drugs (gabapentin, pregabalin), or strong analgesics (tramadol, opioids), ${ }^{42,43}$ and it is entirely reasonable to expect that medications may reduce cognitive test performances, ${ }^{44}$ thus making difficult to distinguish which deficits may be attributable to FM and which to drugs. A final limitation is that the analysis was based on a population of adults from a relatively limited geographical area in central and northern Italy.

\section{Conclusion}

We have identified three subgroups of FM samples in a large cohort of FM using an Internet survey. Cluster 1 had the lowest mean total FIQR score, which also fell within the mild symptom severity range of the FIQR, whereas cluster 3 was characterized by severe symptoms, cluster 2 captured moderate symptoms with mild levels of cognitive/ psychological symptoms. Web surveys allow rapid updating of questionnaire content and question ordering according to user responses and could provide rationale to support the study of individualized clinical evaluation and may be used to identify optimal treatment strategies.

\section{Acknowledgments}

We are very grateful to all patients who kindly completed the questionnaires on the Website. Furthermore, we wish to thank Advice Pharma Group (www.advicepharma.com) and Appycom S.r.l. (http://www.appycom.it/site) for the creation of the web-portal and the technical assistance provided during the study.

\section{Author contributions}

All authors contributed toward data analysis, drafting and critically revising the paper and agree to be accountable for all aspects of the work. FS was the principal investigator, was responsible for the everyday coordination and management of the study, created and managed the data collection web platform, analyzed the data, and contributed to writing the manuscript. FM and PSP participated in conceiving the study, provided clinical support, and were involved in the study design. AD, MDC, AC, and FA provided clinical support and contributed to writing the manuscript. $\mathrm{AD}, \mathrm{AC}$, and $\mathrm{RC}$ participated in data acquisition of data and were involved in revising the intellectual content of the paper. All of the authors have read and approved the final paper.

\section{Disclosure}

The authors report no conflicts of interest in this work.

\section{References}

1. Mease P. Fibromyalgia syndrome: review of clinical presentation, pathogenesis, outcome measures, and treatment. J Rheumatol Suppl. 2005;32(Suppl):S6-S21.

2. Salaffi F, De Angelis R, Grassi W; MArche Pain Prevalence, INvestigation Group (MAPPING) study. Prevalence of musculoskeletal conditions in an Italian population sample: results of a regional community-based study. I. The MAPPING study. Clin Exp Rheumatol. 2005;23(6): 819-828.

3. Wolfe F, Brähler E, Hinz A, Häuser W. Fybromyalgia prevalence, somatic symptom reporting, and the dimensionality of polysymptomatic distress: results from a survey of the general population. Arthritis Care Res (Hoboken). 2013;65(5):777-785.

4. Mease PJ, Arnold LM, Crofford LJ, et al. Identifying the clinical domains of fibromyalgia: contributions from clinician and patient Delphi exercises. Arthritis Rheum. 2008;59(7):952-960.

5. Ambrose KR, Gracely RH, Glass JM. Fibromyalgia dyscognition: concepts and issues. Reumatismo. 2012;64(4):206-215.

6. Bennett RM, Russell J, Cappelleri JC, Bushmakin AG, Zlateva G, Sadosky A. Identification of symptom and functional domains that fibromyalgia patients would like to see improved: a cluster analysis. BMC Musculoskelet Disord. 2010;11:134. 
7. Hurtig IM, Raak RI, Kendall SA, Gerdle B, Wahren LK. Quantitative sensory testing in fibromyalgia patients and in healthy subjects: identification of subgroups. Clin J Pain. 2011;17(4):316-322.

8. Giesecke T, Williams DA, Harris RE, et al. Subgrouping of fibromyalgia patients on the basis of pressure-pain thresholds and psychological factors. Arthritis Rheum. 2003;48(10):2916-2922.

9. Hamilton NA, Karoly P, Zautra AJ. Health goal cognition and adjustment in women with fibromyalgia. J Behav Med. 2005;28(5):455-466.

10. Borg C, Padovan C, Thomas-Antérion C, et al. Pain-related mood influences pain perception differently in fibromyalgia and multiple sclerosis. J Pain Res. 2014;7:81-87.

11. Thieme K, Turk DC. Heterogeneity of psychophysiological stress responses in fibromyalgia syndrome patients. Arthritis Res Ther. 2006;8(1):R9.

12. Malin K, Littlejohn GO. Psychological control is a key modulator of fibromyalgia symptoms and comorbidities. J Pain Res. 2012;5:463-471.

13. de Souza JB, Goffaux P, Julien N, Potvin S, Charest J, Marchand S. Fibromyalgia subgroups: profiling distinct subgroups using the Fibromyalgia Impact Questionnaire. A preliminary study. Rheumatol Int. 2008;29(5):509-515.

14. Häuser W, Akritidou I, Felde E, et al. Steps towards a symptom-based diagnosis of fibromyalgia syndrome. Symptom profiles of patients from different clinical settings. Z Rheumatol. 2008;67(6):511-515.

15. Vincent A, Hoskin TL, Whipple MO, et al. OMERACT-based fibromyalgia symptom subgroups: an exploratory cluster analysis. Arthritis Res Ther. 2014;16(5):463.

16. Aldenderfer MS, Blashfield RK. Cluster Analysis. Newbury Park, CA: Sage Publications, Inc; 1984.

17. Salaffi F, Sarzi-Puttini P, Girolimetti R, Atzeni F, Gasparini S, Grassi W. Health-related quality of life in fibromyalgia patients: a comparison with rheumatoid arthritis patients and the general population using the SF-36 health survey. Clin Exp Rheumatol. 2009;27(Suppl 56):S67-S74.

18. Choy EH, Arnold LM, Clauw DJ, et al. Content and criterion validity of the preliminary core dataset for clinical trials in fibromyalgia syndrome. J Rheumatol. 2009;36(10):2330-2334.

19. Bennett RM, Friend R, Jones KD, Ward R, Han BK, Ross RL. The Revised Fibromyalgia Impact Questionnaire (FIQR): validation and psychometric properties. Arthritis Res Ther. 2009;11(4):R120.

20. Salaffi F, Franchignoni F, Giordano A, Ciapetti A, Sarzi-Puttini P, Ottonello M. Psychometric characteristics of the Italian version of the revised Fibromyalgia Impact Questionnaire using classical test theory and Rasch analysis. Clin Exp Rheumatol. 2013;31(Supp1 79):S41-S49.

21. Dellifraine JL, Dansky KH. Home-based telehealth: a review and metaanalysis. J Telemed Telecare. 2008;14(2):62-66.

22. Meystre S. The current state of telemonitoring: a comment on the literature. Telemed J E Health. 2005;11(1):63-69.

23. Paré G, Jaana M, Sicotte C. Systematic review of home telemonitoring for chronic diseases: the evidence base. J Am Med Inform Assoc. 2007;14(3):269-277.

24. Roine R, Ohinmaa A, Hailey D. Assessing telemedicine: a systematic review of the literature. CMAJ. 2001;165(6):765-771.

25. Demiris G, Afrin LB, Speedie S, et al. Patient-centered applications: use of information technology to promote disease management and wellness. A white paper by the AMIA knowledge in motion working group. J Am Med Inform Assoc. 2008;15(1):8-13.

26. Williams DA, Kuper D, Segar M, Mohan N, Sheth M, Clauw DJ. Internet-enhanced management of fibromyalgia: a randomized controlled trial. Pain. 2010;151(3):694-702.

Journal of Pain Research

\section{Publish your work in this journal}

The Journal of Pain Research is an international, peer-reviewed, open access, online journal that welcomes laboratory and clinical findings in the fields of pain research and the prevention and management of pain. Original research, reviews, symposium reports, hypothesis formation and commentaries are all considered for publication.

Submit your manuscript here: http://www.dovepress.com/journal-of-pain-research-journal
27. Wolfe F, Clauw DJ, Fitzcharles MA, et al. The American College of Rheumatology preliminary diagnostic criteria for fibromyalgia and measurement of symptom severity. Arthritis Care Res (Hoboken). 2010;62(5):600-610.

28. Salaffi F, Sarzi-Puttini P, Girolimetti R, Gasparini S, Atzeni F, Grassi W. Development and validation of the self-administered fibromyalgia assessment status: a disease-specific composite measure for evaluating treatment effect. Arthritis Res Ther. 2009;11(4):R125.

29. Burckhardt CS, Clark SR, Bennett RM. The Fibromyalgia Impact Questionnaire: development and validation. J Rheumatol. 1991;18(5): 728-733.

30. Bennett RM, Bushmakin AG, Cappelleri JC, Zlateva G, Sadosky AB. Minimal clinically important difference in the fibromyalgia impact questionnaire. J Rheumatol. 2009;36(6):1304-1311.

31. Streiner DL, Norman GR. Methods of administration. In: Health Measurement Scales: A Practical Guide to Their Development and Use. 2nd ed. New York: Oxford Medical; 1995:189-205.

32. Bennett RM, Jones J, Turk DC, Russell IJ, Matallana L. An internet survey of 2,596 people with fibromyalgia. BMC Musculoskelet Disord. 2007;8:27.

33. Chandran A, Schaefer C, Ryan K, Baik R, McNett M, Zlateva G. The comparative economic burden of mild, moderate, and severe fibromyalgia: results from a retrospective chart review and crosssectional survey of working-age U.S. adults. J Manag Care Pharm. 2012;18(6):415-426.

34. Perrot S, Schaefer C, Knight T, Hufstader M, Chandran AB, Zlateva G. Societal and individual burden of illness among fibromyalgia patients in France: association between disease severity and OMERACT core domains. BMC Musculoskelet Disord. 2012;13:22.

35. Schaefer C, Chandran A, Hufstader M, et al. The comparative burden of mild, moderate and severe fibromyalgia: results from a cross-sectional survey in the United States. Health Qual Life Outcomes. 2011;9:71.

36. Wilson HD, Robinson JP, Turk DC. Toward the identification of symptom patterns in people with fibromyalgia. Arthritis Rheum. 2009;61(4):527-534.

37. Docampo E, Collado A, Escaramì G, et al. Cluster analysis of clinical data identifies fibromyalgia subgroups. PLoS One. 2013;8(9):e74873.

38. Kuner R. Central mechanisms of pathological pain. Nat Med. 2010;16(11): 1258-1266.

39. Slobodin G, Reyhan I, Avshovich N, et al. Recently diagnosed axial spondyloarthritis: gender differences and factors related to delay in diagnosis. Clin Rheumatol. 2011;30(8):1075-1080.

40. Moriarty O, McGuire BE, Finn DP. The effect of pain on cognitive function: a review of clinical and preclinical research. Prog Neurobiol. 2011;93(3):385-404.

41. Williams DA, Clauw DJ, Glass JM. Perceived cognitive dysfunction in fibromyalgia syndrome. J Musculoskelet Pain. 2011;19(2):66-75.

42. Sommer C, Hauser W, Alten R, et al. [Drug therapy of fibromyalgia syndrome. Systematic review, meta-analysis and guideline]. Schmerz. 2012;26(3):297-310.

43. Peng X, Robinson RL, Mease P, et al. Long-term evaluation of opioid treatment in fibromyalgia. Clin J Pain. 2015;31(1):7-13.

44. Miró E, Lupiáñez J, Hita E, Martínez MP, Sánchez AI, Buela-Casal G. Attentional deficits in fibromyalgia and its relationships with pain, emotional distress and sleep dysfunction complaints. Psychol Health. 2011;26(6):765-780.

The manuscript management system is completely online and includes a very quick and fair peer-review system, which is all easy to use. Visit http://www.dovepress.com/testimonials.php to read real quotes from published authors. 